\title{
Malignant Eye Neoplasm
}

National Cancer Institute

\section{Source}

National Cancer Institute. Malignant Eye Neoplasm. NCI Thesaurus. Code C4767.

A primary or metastatic malignant neoplasm involving the structures of the eye

(conjunctiva, cornea, uvea, retina), the lacrimal gland, and the eyelid. Representative examples include melanoma, carcinoma, lymphoma, and retinoblastoma. 